\title{
Formulation and Evaluation of Swellable Oral Thin Film of Metoclopramide Hydrochloride
}

\author{
Marzia Alam, Farhana Tasneem and Md. Saiful Islam Pathan \\ Department of Pharmacy, State University of Bangladesh, Dhanmondi, Dhaka-1209, Bangladesh
}

\begin{abstract}
Traditionally metoclopramide hydrochloride is used as an antiemetic in migraine \& cancer patients and in controlling post-operative nausea and vomiting. The main aim of this study was to develop a swellable oral thin film for the treatment of the mentioned pathological conditions. This swellable thin film formulation is specially designed for paediatric patients for oral administration, where it will swell up when exposed to saliva in the oral cavity and will be easily swallowed by the patient, without the need for water. Nine formulations of swellable oral thin film of metoclopramide hydrochloride such as $\mathrm{F}_{1}$ to $\mathrm{F}_{9}$ were prepared by solvent casting method. The drug-Povidone K90 ratio were 1:1, 1:2, 1:3, 1:4, 1:5, 1:6, 1:7, 1:8 and 1:9, respectively. Various physicochemical evaluations including weight variation, thickness, folding endurance, in vitro dissolution studies, content uniformity, FTIR, Trinocular microscopic imaging and swelling property of film were conducted. It was observed that thickness and weight of film was directly proportional to the total solid content of the film $\left(\mathrm{F}_{1}\right.$ showed the lowest thickness and weight and $\mathrm{F}_{9}$ showed the highest). All the batches revealed content uniformity between $98.0 \%$ to $101.0 \%$ and cumulative drug release between $94.8 \%$ and $102.4 \%$. Swelling behavior of film was inversely proportional to the quantity of Povidone K90 in the film. Formulation $\mathrm{F}_{1}$ showed the highest linear expansion co-efficient (L\%) and percentage increase in weight due to swelling while $\mathrm{F}_{9}$ demonstrated the lowest corresponding to the quantity of Povidone K90. Quantity of glycerin and Povidone K90 affected the appearance and peeling of the films. $F_{1}, F_{2}$ and $F_{3}$ had lowest quantity of glycerin and Povidone $\mathrm{K} 90$ and were least glossy and easier to peel out and $\mathrm{F}_{7}, \mathrm{~F}_{8}$ and $\mathrm{F}_{9}$ with highest quantity of glycerin and Povidone K90 and were glossiest but hardest to peel out.
\end{abstract}

Key words: Formulation, Evaluation, Swellable Oral Thin Film, Metoclopramide Hydrochloride.

\section{Introduction}

Oral administration is the most popular route due to ease of ingestion, pain avoidance, versatility (to accommodate various types of drug candidates), and most importantly, patient compliance. In addition, solid oral delivery systems do not require sterile conditions and are, therefore, less expensive to manufacture. Several novel technologies for oral delivery have recently become available to address the physicochemical and pharmacokinetic characteristics of drugs, while improving patient compliance. The administration of medicinal products in patients depends principally on age, physical development and ability to coordinate but also to psychological development and understanding (Committee for medicinal and products for human use, 2006). The administration of medications to pediatric patients is difficult in many ways because the health care providers and parents face many challenges not experienced, or experienced to a lesser degree, than when medications are prescribed for and taken by adults. Firstly, less information is available about the use of most medications for pediatric patients. In fact, only about $20 \%$ of drugs marketed in the United States have labeling for pediatric use. Secondly, many drugs that are used for some pediatric patients are not in appropriate dosage forms for use by children. This includes even some medications approved for use in pediatric patients (Sagraves, 2006). A major concern is at what age children can safely swallow solid oral dosage forms such as tablets or capsules is not clearly defined. There resulted the need for diverse solid oral dosage forms for pediatric population. Oral thin films (Hideaki et al., 2008) are novel drug delivery systems especially suitable for both pediatric and geriatric patients who experience difficulties in swallowing traditional solid oral dosage forms (Committee for medicinal and products for human use, 2006). Difficulty in swallowing 
(dysphasia) is common among all age groups, especially in elderly, and is also seen in swallowing conventional tablets and capsules. Dysphasia is associated with many medical conditions, including stroke, Parkinson's disease, AIDS, thyroidectomy, head and neck radiation therapy, and other neurological disorders, including cerebral palsy. The most common complaint are tablet size, followed by surface, form and taste. The problem of swallowing tablets was more evident in geriatric and pediatric patients, as well as travelling patients who may not have ready access to water (Committee for medicinal and products for human use, 2006). USP (2012) defines films as "thin sheets that are placed in the oral cavity. They contain one or more layers. A layer may or may not contain a drug substance". Oral thin film is one sub-category of pharmaceutical film. Oral thin films are novel oral drug delivery system. These drug delivery systems are rapidly gaining interest in the pharmaceutical industry because they either dissolve or disintegrate generally within a minute without water or chewing. These systems offer superior clinical profiles with potential oromucosal absorption thus increasing the drug bioavailability with respect to other routes of oral administration.

Research and development in the oral drug delivery segment have to transition of dosage forms from simple conventional tablets/capsules to orally disintegrating tablet (ODT) to wafer to the recent development of oral films
(ODF). A number of molecules can be incorporated into this delivery system. They may include cough/cold remedies (antitussives, expectorants), sore throat, erectile dysfunction drugs, antihistaminic, antiasthamatics, gastrointestinal drugs, nausea, pain and CNS (e.g. antiparkinsons disease), caffeine strips, snoring aid, multivitamins, sleeping aid etc. In the present study, a traditional antiemetic drug metoclopramide hydrochloride was chosen as the model drug. Metoclopramide hydrochloride is a dopaminergic blocker of BCS class III drug. It promotes gut motility by inhibiting presynaptic and postsynaptic $\mathrm{D}_{2}$ receptors as well as presynaptic 5$\mathrm{HT}_{4}$ receptors. Metoclopramide also produces antiemetic effects by inhibition of $\mathrm{D}_{2}$ and $5-\mathrm{HT}_{3}$ receptors in the CTZ (Chemoreceptor trigger zone).

\section{Materials and Methods}

Metoclopramide hydrochloride was obtained as a gift sample from Opsonin Pharmaceuticals Ltd., Dhaka, Bangladesh. Povidone K90 (Kollidon K90) was obtained from BASF, Germany. Polyvinyl alcohol (98-99\% hydroxylation) and Carbopol 971P, Calcium chloride (anhydrous), Citric acid (anhydrous) and Titanium dioxide was purchased from Merck, India. Sucralose was obtained from Drug International Ltd., Dhaka, Bangladesh. Other ingredients used were of analytical grade.

Table 1. Formulation of swellable oral thin film of metoclopramide hydrochloride.

\begin{tabular}{lccccccccc}
\hline Ingredients (mg) & \multicolumn{7}{c}{ Formulation code } \\
\cline { 2 - 9 } & $\mathrm{F}_{1}$ & $\mathrm{~F}_{2}$ & $\mathrm{~F}_{3}$ & $\mathrm{~F}_{4}$ & $\mathrm{~F}_{5}$ & $\mathrm{~F}_{6}$ & $\mathrm{~F}_{7}$ & $\mathrm{~F}_{8}$ & $\mathrm{~F}_{9}$ \\
\hline Metoclopramide hydrochloride & 5 & 5 & 5 & 5 & 5 & 5 & 5 & 5 & 5 \\
Povidone K90 & 5 & 10 & 15 & 20 & 25 & 30 & 35 & 40 & 45 \\
Glycerin & 0.25 & 0.25 & 0.25 & 0.40 & 0.40 & 0.40 & 0.55 & 0.55 & 0.55 \\
Sucralose & 1 & 1 & 1 & 1 & 1 & 1 & 1 & 1 & 1 \\
Citric acid (anhydrous) & 0.2 & 0.2 & 0.2 & 0.2 & 0.2 & 0.2 & 0.2 & 0.2 & 0.2 \\
Titanium dioxide & 0.6 & 0.6 & 0.6 & 0.6 & 0.6 & 0.6 & 0.6 & 0.6 & 0.6 \\
Distilled water & 173.3 & 173.3 & 173.3 & 173.3 & 173.3 & 173.3 & 173.3 & 173.3 & 173.3 \\
Polyvinyl alcohol & 9.7 & 9.7 & 9.7 & 9.7 & 9.7 & 9.7 & 9.7 & 9.7 & 9.7 \\
Carbopol 971P & 3.2 & 3.2 & 3.2 & 3.2 & 3.2 & 3.2 & 3.2 & 3.2 & 3.2 \\
Glycerin & 0.5 & 0.5 & 0.5 & 0.5 & 0.5 & 0.5 & 0.5 & 0.5 & 0.5 \\
Calcium chloride (anhydrous) & 0.1 & 0.1 & 0.1 & 0.1 & 0.1 & 0.1 & 0.1 & 0.1 & 0.1 \\
Sucralose & 0.5 & 0.5 & 0.5 & 0.5 & 0.5 & 0.5 & 0.5 & 0.5 & 0.5 \\
Distilled water & 534.00 & 534.00 & 534.00 & 534.00 & 534.00 & 534.00 & 534.00 & 534.00 & 534.00 \\
\hline
\end{tabular}

Method of preparation of swellable oral thin film:The drug layer was prepared by dissolving citric acid (anhydrous) in distilled water taken in a beaker. Titanium dioxide was added to the solution and homogenized for 5 
minutes. Povidone K90 was added gradually and mixed using homogenizer. Glycerin and sucralose was added and homogenized for 5 minutes. Finally, required quantity of metoclopramide $\mathrm{HCl}$ was added and mixed well for 15 minutes to dissolve completely.

To prepare the gelling layer accurately weighed quantity of $\mathrm{CaCl}_{2}$ was dissolved in distilled water. To this solution carbopol 971P was gradually added and homogenized to dissolve completely to prepare the gelling solution. Polyvinyl alcohol was added and heated to dissolve. Lastly glycerin and sucralose were added to this and homogenized well. The order of material addition and dissolution was strictly maintained to obtain a gelling solution of consistent quality. The solution was kept aside until the bubbles were disappeared. Then required quantity of gelling layer solution was casted onto glass plate very carefully avoiding formation of bubbles and ensuring uniform distribution.
The casted plates were oven dried at $55-60^{\circ} \mathrm{C}$ for $3.5-$ 4 hours or until drying. Two plates were casted for each swellable film. One is the bottom gelling layer and another is the top gelling layer. The required quantity of drug layer was casted onto the bottom gelling layer carefully and uniformly, avoiding formation of bubbles. The drug layer was dried in hot air oven at $50-55^{\circ} \mathrm{C}$ for about 120 minutes and the drug layer was removed from the oven when stickiness remained.

To prepare the swellable oral thin film, the top gelling layer was removed from the plate very carefully to avoid any damage to the film. The top gelling layer was then placed carefully on the drug layer. This swellable film was dried in hot air oven at $50-55^{\circ} \mathrm{C}$ until LOD was met but the film did not become crispy. The dried film (Figure 1) was then removed from the plate and cut into the desired size and shape.

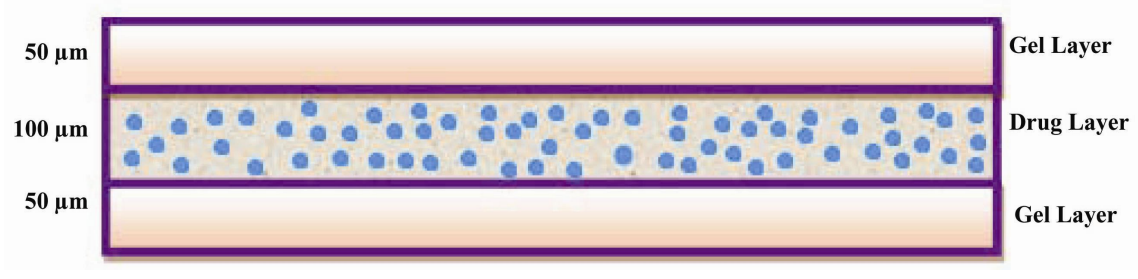

Figure 1. Schematic diagram of swellable oral thin film of metocloramide hydrochloride.

Morphological properties of film: Properties such as homogeneity, color, transparency and surface of the oral films were evaluated by visual inspection (Raju et al., 2011; Prabhakara et al., 2008).

Mass of swellable oral thin film of metoclopramide $\mathrm{HCl}$ : Mass of individual films was studied by taking randomly selected films and individually weighting 10 thin films and calculating the average mass. The standard deviation was calculated. The individual mass should not deviate significantly from the average weight.

Thickness of film: The thickness of the film sample was measured using a micrometer (Digimatic Micrometer, Mitutoyo, Tokyo, Japan) at five locations (centre and 4 corners). The mean thickness and relative standard deviation was calculated.

Folding endurance: The folding endurance is expressed as the number of folds either to break a specimen or to develop visible cracks. It was determined by repeatedly folding a patch of $20 \times 20 \mathrm{~mm}$ size at the same place until it broke (Narsimha et al., 1997). Three films of each formulation of size $(10 \mathrm{~mm} \times 20 \mathrm{~mm})$ were cut by using a sharp blade. Folding endurance was determined by repeatedly folding a small strip of film at the same place until it broke. The number of times the film can be folded at the same place without breaking gave the value of folding endurance. The mean value of three readings and standard deviation were then calculated.

Surface $p H$ study: The surface $\mathrm{pH}$ of films is determined to investigate the possible side effect because of change in $\mathrm{pH}$ in vivo, since an acidic or alkaline $\mathrm{pH}$ may cause irritation to buccal mucosa. The film to be tested was placed in a Petri dish and was moistened with $0.5 \mathrm{~mL}$ of distilled water and kept for $30 \mathrm{~s}$. The $\mathrm{pH}$ was noted after bringing the $\mathrm{pH}$ paper in contact with the surface of the formulation and allowing equilibrating for 1 min (Kumar et al., 2005). 


\section{Measurement of swelling property of the film}

Linear expansion co-efficient of film: The film $(1 \times 1$ $\mathrm{cm}^{2}$ ) was placed in a petridish and immersed in $10 \mathrm{ml}$ of distilled water. Specimens were taken at 30, 40, 60, 80, $100,120,140,160$ and 180 seconds and the size of the side length was measured. The linear expansion coefficient ( $\mathrm{L}$ ) was defined as $\mathrm{L}(\%)=\mathrm{L}_{1}-\mathrm{L}_{0} / \mathrm{L}_{0} \times 100$, where $\mathrm{L}_{1}=$ side length of the film after immersion and $\mathrm{L}_{0}=$ the side length of the film before immersion (Ahmed et al., 2010).

Amount absorbed in distilled water: The gelating layer $\left(1 \mathrm{~cm} \times 1 \mathrm{~cm}\right.$ square) was weighed $\left(\mathrm{W}_{1}\right)$ and put in a pre-weighed cover slip. It was kept in a petridish and 10 $\mathrm{ml}$ of distilled water was added. After every 10 seconds, the cover slip was removed and weighed up to 3 minutes. The increase in weight due to absorption of water and swelling of film (Okabe et al., 2008) was defined as

$$
\mathrm{W}(\mathrm{g} / \mathrm{g})=\frac{\left(\mathrm{W}_{2}-\mathrm{W}_{1}-\mathrm{W}_{3}\right)}{\mathrm{W}_{1}}
$$

where, $\mathrm{W}_{1}=$ Initial weight of the film, $\mathrm{W}_{2}=$ Weight of the film after absorption of water, $\mathrm{W}_{3}=$ Weight of the cover slip.

In vitro dissolution test: The in vitro drug release study was carried out using USP 23 type-I basket type dissolution test apparatus in $900 \mathrm{ml}$ of phosphate buffer (pH 6.8) at 50 RPM. The temperature of the medium was set at $37 \pm 2^{\circ} \mathrm{C}$ and number of films per evaluation was three. Aliquots of $5 \mathrm{ml}$ were withdrawn and the sample volume replaced with an equal volume of fresh dissolution medium. The samples were analysed spectrophotometrically at $273 \mathrm{~nm}$. Film samples of $200 \mathrm{~mm}^{2}(20 \mathrm{~mm} \times$ $10 \mathrm{~mm}$ ) were placed in the basket. $5 \mathrm{ml}$ of sample was taken at an interval of 5, 10, 15 and 20 minutes and the same amount was replaced with fresh buffer. The withdrawn samples were filtered through Whatman filter paper and then $1 \mathrm{ml}$ of the filtrate was further diluted to 10 $\mathrm{ml}$ with the same medium and analyzed by using a spectrophotometer at a wavelength of $273 \mathrm{~nm}$. The cumulative percentage release for different formulations was calculated. The relationship between time and percentage release was plotted.

Assay for drug content: The assay was performed to ensure the drug loading onto each film. This test was performed by dissolving a $2 \mathrm{~cm}^{2}$ area of film in $100 \mathrm{ml}$ of phosphate buffer $\mathrm{pH} 6.8$ solution by sonicating in an ultrasonic bath for 15 minutes. The resultant solution was further filtered using a Whatman filter paper, and the filtrate was diluted to $100 \mathrm{ml}$ with same solution in a volumetric flask. Then $2 \mathrm{ml}$ of the filtrate was further diluted to $10 \mathrm{ml}$ with phosphate buffer $\mathrm{pH}$ 6.8. The solution was analyzed with a spectrophotometer at 273 nm.

\section{Content uniformity}

Six (6) films were weighed and taken separately in $100 \mathrm{ml}$ volumetric flask and filled with $50 \mathrm{ml}$ phosphate buffer $\mathrm{pH}$ 6.8. and sonicated for 15 minutes to dissolve completely. The solution was made up to the mark and filtered using Whatman filter paper. The sample solution was diluted 25 times and drug content was determined spectrophotometrically at $273 \mathrm{~nm}$.

FTIR studies of metoclopramide hydrochloride swellable oral thin film: Appropriate quantity of $\mathrm{KBr}$ and sample (in the ratio 200:0.1) were mixed by grinding in an agate mortar. Pellets were made with $100 \mathrm{mg}$ mixture. FTIR spectra were recorded with FT-IR 8400S Shimadzu spectrophotometer in the range 4000-400 $\mathrm{cm}^{-1}$ (Resolution: $2 \mathrm{~cm}^{-1}$ and number of scans was 30 times) (Shahriar et al., 2013; Sultana et al. 2013).

Trinocular microscopic imaging of metoclopramide hydrochloride swellable oral thin film: Trinocular microscopic image of swellable oral thin film of metoclopramide hydrochloride was taken and evaluated. The surface of the film and distribution of polymer and drug within the film was examined.

\section{Results and Discussion}

Swellable oral thin films of metoclopramide hydrochloride were prepared by solvent casting method using different povidone $\mathrm{K} 90$ concentrations in the drug layer. Glycerin was used as the plasticizer. Titanium dioxide was used as an opacifying/tinting agent; citric acid (anhydrous) was used as saliva stimulating agent and sucralose as the sweetening agent. The gelling layer composition was kept constant for all the formulations from F1 to F9 and contained polyvinyl alcohol as the gelforming polymer and Carpobol 971P as the swelling agent. Calcium chloride was used as complexing agent, which formed complex with the carboxyl group of polyvinyl alcohol. The solvent system used was water. 
Mass of film: The mass of the film formulations varied proportionally with the solid content of the film. $\mathrm{F}_{1}$ having the lowest solid content $(26.05 \mathrm{mg})$ has the lowest mass and $\mathrm{F}_{9}$ having the highest solid content $(66.35 \mathrm{mg})$ has the highest weight. The formulated swellable oral thin films had mass variation within the range of pharmacoeial specifications. Figure 2 shows the comparative values of mass of film using different quantities of polymer in drug layer.
Thickness of film: The increase in thickness was directly proportional to the solid content of the film formulation. $F_{1}$ having the lowest solid content $(26.05 \mathrm{mg})$ has the lowest thickness and $F_{9}$ having the highest solid content $(66.35 \mathrm{mg})$ has the highest thickness. Figure 3 shows the comparative values of thickness of film using different quantities of polymer in drug layer.

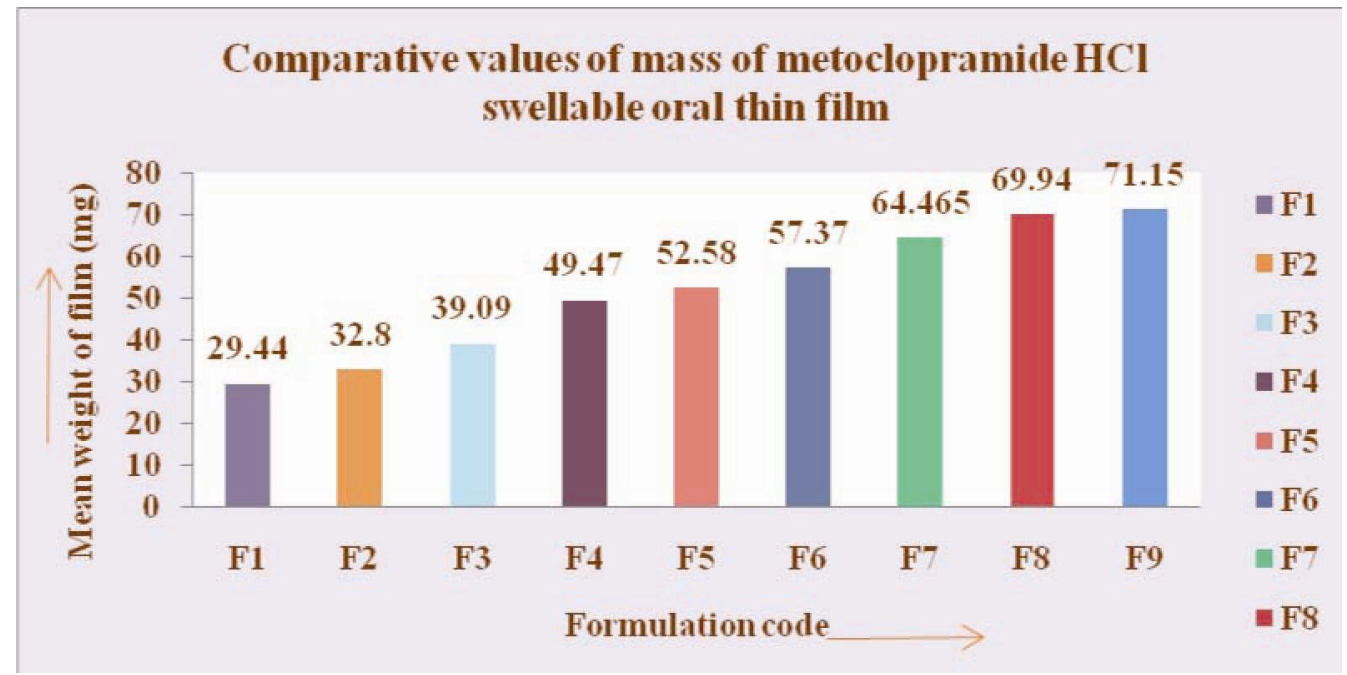

Figure 2. Comparative values of mass of metoclopramide $\mathrm{HCl}$ swellable oral thin film.

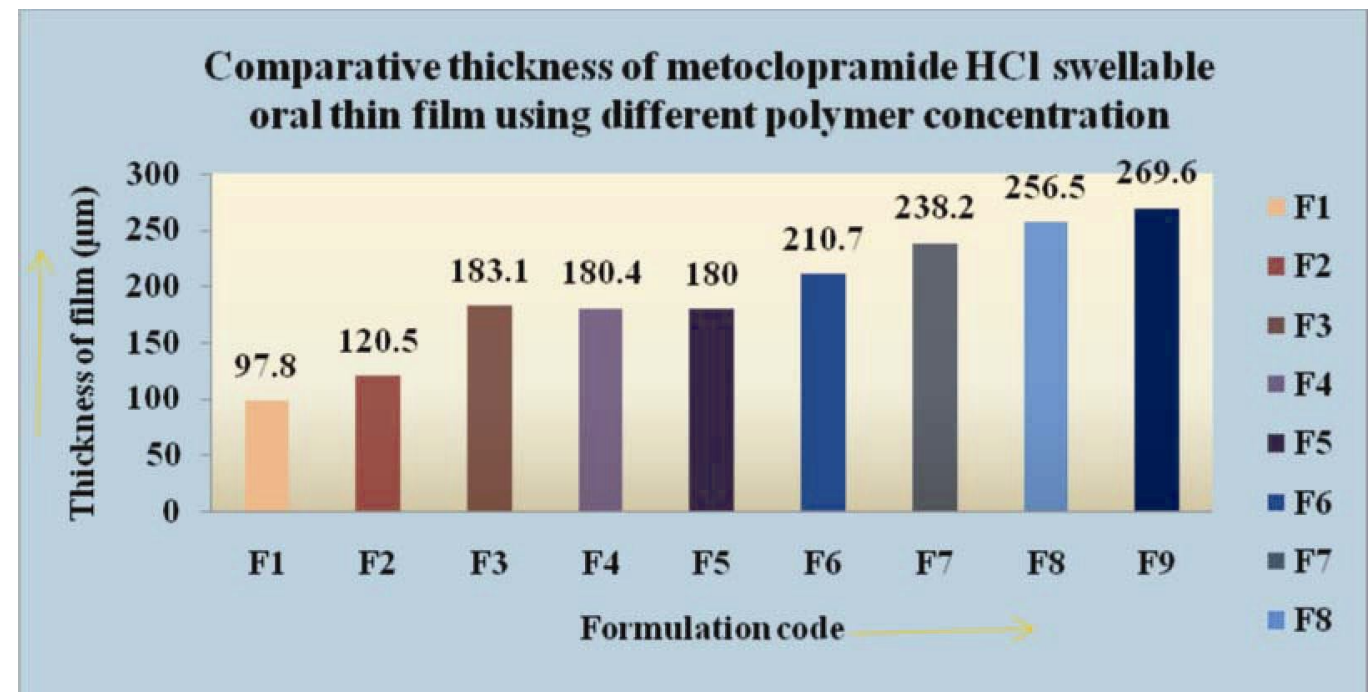

Figure 3. Comparative thickness of metoclopramide $\mathrm{HCl}$ swellable oral thin film using different polymer concentration.

Folding endurance: The folding endurance of the formulated films was above 500 times of folding which indicates satisfactory mechanical strength.
Swelling behavior of film: The swelling behaviour of the film was a function of quantity of povidone K 90 in the drug layer. An inverse relationship was found to exist between linear expansion (percentage L) and quantity of 
Povidone K90 polymer. $F_{1}$ had the highest $F_{1}$ had the highest percentage of $50.167 \%$ and $\mathrm{F}_{9}$ had the lowest $\mathrm{L} \%$ of $5.00 \%$. The mean values of $\%$ mass increase for $\mathrm{F}_{1}$ is $740.80 \%, \mathrm{~F}_{2}$ is $441.50 \%, \mathrm{~F}_{3}$ is $570.60 \%, \mathrm{~F}_{4}$ is $269.40 \%, \mathrm{~F}_{5}$ is $230.00 \%, \mathrm{~F}_{6}$ is $317.40 \%, \mathrm{~F}_{7}$ is $271.62 \%, \mathrm{~F}_{8}$ is $294.4 \%$ and $\mathrm{F}_{9}$ is $224.4 \%$. The amount of water absorbed by film was also inversely proportional to quantity of Povidone K90 polymer. Figure 4 shows the swelling behaviour of metoclopramide swellable oral thin film at different times $(1,2,3,4,5$ and 6 minutes). Figures 5 and 6 show the linear expansion co-efficient of film, linear expansion coefficient of gelling layer and the amount of water absorbed by film respectively. Tables 2,3 and 4 show the comparative data of linear expansion coefficient of formulations $\mathrm{F}$ 1 to $\mathrm{F} 9$, linear expansion co-efficient values of gelling layer and amount of water absorbed by film respectively.

In vitro dissolution: All the film formulations showed release pattern similar immediate release dosage forms. In first 5 minutes, the formulations show $11.0 \%$ to $24.00 \%$ release. No formulation showed percentage cumulative release more than $84 \%$ in the first 15 minutes. However, $100 \%$ drug release was observed within 20 minutes for all the formulations (Figure 7). Table 5 shows the cumulative drug release at definite time intervals.

Swelling property of the gelling layer: The following table shows the linear expansion co-efficient (L \%) of the gelling layer. It appears from the data that the linear expansion of gelling layer alone is higher than the film as a whole. The highest linear expansion was observed in $F_{1}$ $(50.167 \%)$, but the gelling layer showed a linear expansion co-efficient of $67.00 \%$

Content uniformity of film: All the formulated batches had percent drug content between $98.0 \%$ to $101.0 \%$ (Figure 8). The standard deviation values of all batches were below 1.00, which indicates content uniformity of the film formulations.

\section{FT-IR studies}

FT-IR studies of film showed (Figures 9 and 10) slight changes in peaks compared to the metoclopramide hydrochloride standard, which needs further study.

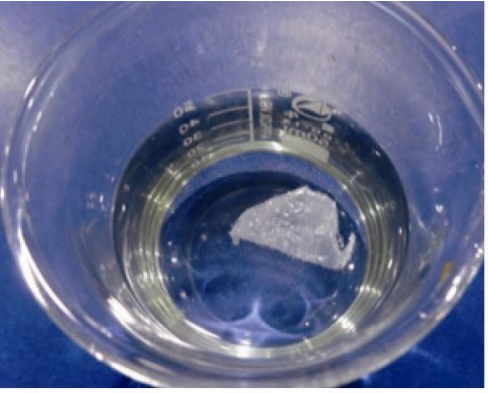

Figure i: 1 minute

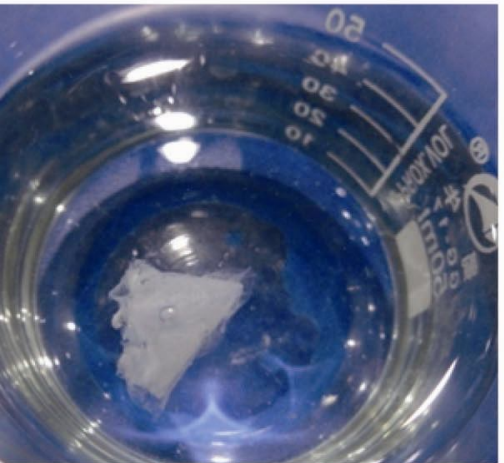

Figure iv: $\mathbf{4}$ minutes

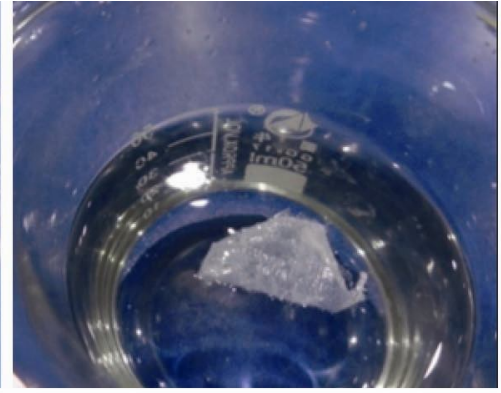

Figure ii: 2 minutes

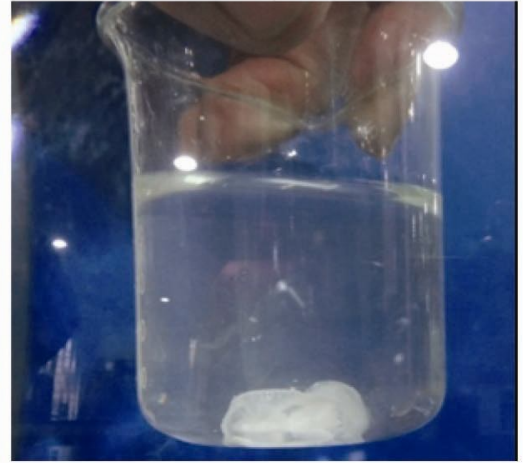

Figure v: 5 minutes

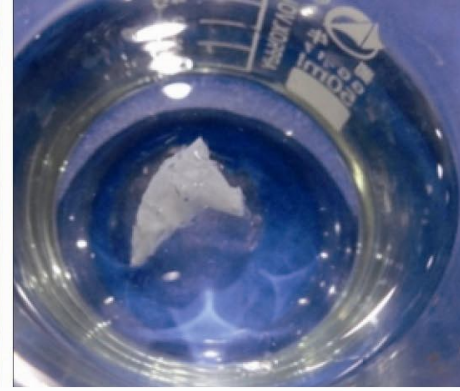

Figure iii: 3 minutes

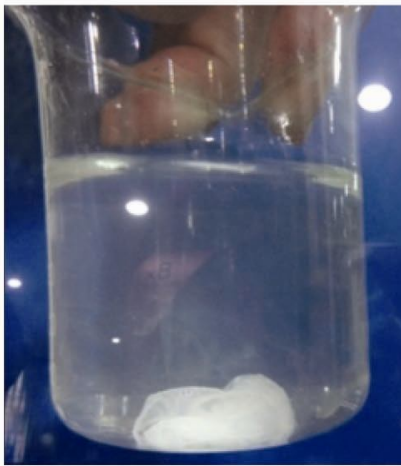

Figure iv: 6 minutes

Figure 4. Swelling behaviour of metoclopramide swellable oral thin film at different times. 
Table 2. Linear expansion co-efficient of formulations F1 to F9.

\begin{tabular}{|c|c|c|c|c|c|c|c|c|c|c|c|c|}
\hline \multirow{2}{*}{$\begin{array}{l}\text { S1. } \\
\text { No. }\end{array}$} & \multirow[t]{2}{*}{ F Code } & \multicolumn{9}{|c|}{ Measure of side length $(\mathrm{mm})$ with time $(\mathrm{sec})$} & \multirow{2}{*}{$\begin{array}{c}\text { Linear } \\
\text { expansion co- } \\
\text { efficient (L\%) }\end{array}$} & \multirow{2}{*}{$\begin{array}{c}\text { Mean value } \pm \\
\text { S.D. } \\
n=3\end{array}$} \\
\hline & & 0 & 30 & 40 & 60 & 80 & 100 & 120 & 140 & 180 & & \\
\hline \multirow[t]{3}{*}{01} & F1 & 10 & 11 & 13 & 14 & 13.5 & 14 & 14.5 & 14.5 & 15 & 50 & $50.167 \pm 0.289$ \\
\hline & & 10 & 11 & 12 & 13 & 13.5 & 14.5 & 14.5 & 15 & 15.05 & 50.5 & \\
\hline & & 10 & 11 & 12 & 13 & 13.75 & 14 & 14.5 & 14.75 & 15 & 50 & \\
\hline \multirow[t]{3}{*}{02} & $\mathrm{~F} 2$ & 10 & 10 & 13 & 13 & 13 & 14 & 14.05 & 14.25 & 14.5 & 45 & $45.00 \pm 0.00$ \\
\hline & & 10 & 10 & 12 & 12 & 13 & 13.5 & 13.75 & 14.25 & 14.5 & 45 & \\
\hline & & 10 & 10 & 12 & 13 & 13.75 & 14.25 & 14.25 & 14.5 & 14.5 & 45 & \\
\hline \multirow[t]{3}{*}{03} & F3 & 10 & 10.5 & 13 & 13 & 13.5 & 13.75 & 14 & 14 & 14 & 40 & $40.167 \pm 0.289$ \\
\hline & & 10 & 10.5 & 12 & 12 & 12 & 13 & 13.5 & 14 & 14 & 40 & \\
\hline & & 10 & 10.5 & 12 & 13 & 13.5 & 13.5 & 14 & 14.05 & 14.05 & 40.5 & \\
\hline \multirow[t]{3}{*}{04} & F4 & 10 & 10 & 10 & 10 & 10 & 12 & 12.5 & 13.05 & 13.05 & 30.5 & $30.167 \pm 0.289$ \\
\hline & & 10 & 10 & 10 & 10 & 11 & 12 & 12.5 & 13 & 13 & 30 & \\
\hline & & 10 & 10 & 10 & 10 & 11 & 11 & 12 & 12.75 & 13 & 30 & \\
\hline \multirow[t]{3}{*}{05} & F5 & 10 & 10 & 11 & 12 & 12 & 12.5 & 12.5 & 12.5 & 12.5 & 25 & $25.00 \pm 0.00$ \\
\hline & & 10 & 10.5 & 11 & 12 & 12.25 & 12.25 & 12.25 & 12.5 & 12.5 & 25 & \\
\hline & & 10 & 10.5 & 11 & 12 & 12 & 12 & 12.25 & 12.25 & 12.5 & 25 & \\
\hline \multirow[t]{3}{*}{06} & F6 & 10 & 10 & 11 & 11 & 11 & 11.05 & 11.05 & 11.05 & 12 & 20 & $20.167 \pm 0.289$ \\
\hline & & 10 & 10 & 11 & 11 & 10.5 & 10.5 & 11 & 11 & 12 & 20 & \\
\hline & & 10 & 10 & 11 & 11 & 10.5 & 10.5 & 11 & 11.5 & 12.05 & 20.5 & \\
\hline \multirow[t]{3}{*}{07} & F7 & 10 & 10 & 11 & 12 & 12 & 12 & 12 & 12 & 12 & 20 & $20.333 \pm 0.289$ \\
\hline & & 10 & 10.5 & 11 & 11 & 11 & 11.25 & 11.75 & 12.05 & 12.05 & 20.5 & \\
\hline & & 10 & 10.5 & 11 & 11 & 11 & 11.25 & 11.75 & 12 & 12.05 & 20.5 & \\
\hline \multirow[t]{3}{*}{08} & F8 & 10 & 10 & 10 & 10 & 10 & 10.25 & 10.5 & 11 & 11.05 & 10.5 & $10.667 \pm 0.289$ \\
\hline & & 10 & 10 & 10 & 10 & 10.25 & 10.25 & 10.5 & 11 & 11.10 & 11 & \\
\hline & & 10 & 10 & 10 & 10 & 10 & 10.25 & 10.5 & 11 & 11.05 & 10.5 & \\
\hline \multirow[t]{3}{*}{09} & F9 & 10 & 10 & 10 & 10 & 10 & 10 & 10 & 10 & 10.5 & 5 & $5.00 \pm 0.00$ \\
\hline & & 10 & 10 & 10 & 10 & 10 & 10 & 10 & 10 & 10.5 & 5 & \\
\hline & & 10 & 10 & 10 & 10 & 10 & 10 & 10 & 10 & 10.5 & 5 & \\
\hline
\end{tabular}

Comparative linear expansion co-efficient (\% L) of metoclopramide $\mathrm{HCl}$ swellable oral thin film using different polymer concentration

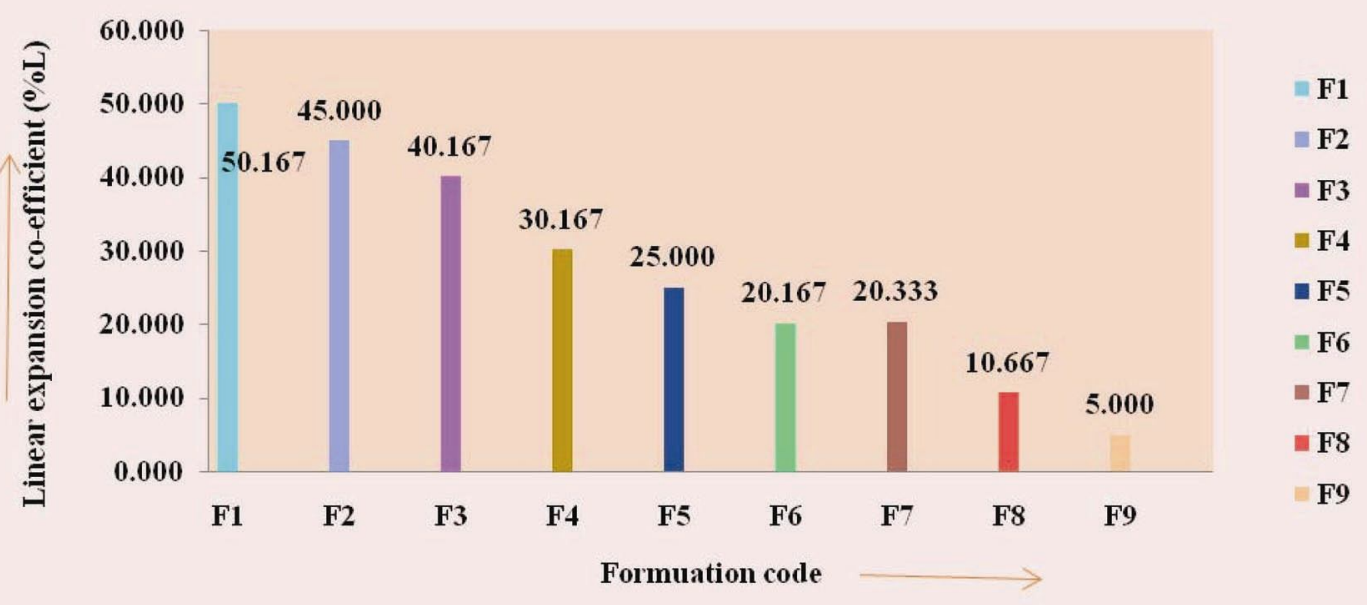

Figure 5. Linear expansion co-efficient of formulations $F_{1}$ to $F_{9}$. 
Table 3. Linear expansion co-efficient of gelling layer.

\begin{tabular}{ccccccccccccc}
\hline $\begin{array}{c}\text { Sl. } \\
\text { No. }\end{array}$ & F Code & \multicolumn{8}{c}{ Measure of side length $(\mathrm{mm})$} & with time $(\mathrm{sec})$ & \multicolumn{2}{c}{$\begin{array}{c}\text { Linear } \\
\text { expansion } \\
\text { co-efficient } \\
\text { (L \%) }\end{array}$} \\
\cline { 2 - 12 } & & 0 & 30 & 40 & 60 & 80 & 100 & 120 & 140 & 180 & $\begin{array}{c}\text { Mean value } \pm \\
\text { S.D. }\end{array}$ \\
\hline 01 & Gelling & 10 & 12 & 12 & 13.5 & 14 & 15 & 15 & 15 & 16.60 & 66.00 & $67.00 \pm 0.866$ \\
& layer & 10 & 12 & 12.75 & 13 & 14 & 15 & 15.3 & 15.8 & 16.75 & 67.50 & \\
& & 10 & 12 & 12.5 & 13 & 14 & 15 & 15.8 & 15.8 & 16.75 & 67.50 \\
\hline
\end{tabular}

Table 4. Amount absorbed in distilled water by film

\begin{tabular}{|c|c|c|c|c|c|c|c|c|c|c|c|c|c|c|c|c|c|}
\hline \multirow{2}{*}{\multicolumn{2}{|c|}{$\begin{array}{l}\text { Sl. } \quad F \\
\text { No. code }\end{array}$}} & \multicolumn{13}{|c|}{ Increase in weight (mg) with time (sec) } & \multirow{2}{*}{$\begin{array}{c}\% \\
\text { increase } \\
\text { (wt.) }\end{array}$} & \multirow{2}{*}{$\begin{array}{l}\text { Mean } \\
\text { value } \\
\pm \text { S.D. }\end{array}$} & \multirow{2}{*}{$\begin{array}{c}\text { Mean value } \\
\pm \text { S.D. } \\
n=3\end{array}$} \\
\hline & & 0 & 10 & 20 & 30 & 40 & 50 & 60 & 70 & 80 & 90 & 100 & 110 & 120 & & & \\
\hline \multirow[t]{3}{*}{01} & F1 & 12 & 160.5 & 164 & 183.3 & 185.2 & 185.2 & 200.5 & 200.5 & 213.7 & 216.2 & 216.2 & 216.2 & 216.2 & 740.00 & & \\
\hline & & 12.2 & 163.7 & 166 & 183 & 185 & 181 & 210 & 211 & 211 & 215.6 & 217.8 & 217.8 & 217.8 & 740.98 & 740.77 & $740.8 \pm 0.69$ \\
\hline & & 12.1 & 170.2 & 171 & 189.9 & 191.7 & 192.2 & 192.8 & 192.8 & 201.1 & 220.7 & 222 & 222 & 221.6 & 741.32 & & \\
\hline \multirow[t]{3}{*}{02} & $\mathrm{~F} 2$ & 17.3 & 148 & 148 & 148.8 & 161.1 & 183.3 & 193 & 197.2 & 205.8 & 210.9 & 210.9 & 210.9 & 210.9 & 441.04 & & \\
\hline & & 18 & 153.3 & 155 & 153 & 165.4 & 190.1 & 195.7 & 200.1 & 210.9 & 213.1 & 215.2 & 216.5 & 216.5 & 441.67 & 441.47 & $441.5 \pm 0.38$ \\
\hline & & 17.5 & 147.7 & 148 & 150.1 & 162.1 & 187.2 & 195.7 & 197.7 & 209.3 & 213.8 & 211.1 & 211.1 & 211.1 & 441.71 & & \\
\hline \multirow[t]{3}{*}{03} & F3 & 19.7 & 219.9 & 229 & 243.4 & 250.7 & 261.5 & 238 & 239.7 & 242.4 & 250.8 & 250.8 & 250.8 & 250.8 & 570.56 & & \\
\hline & & 20 & 152.7 & 179 & 197.7 & 203.4 & 207.3 & 210.5 & 226.6 & 240.5 & 252.1 & 252.1 & 252.1 & 249.4 & 571.00 & 570.57 & $570.6 \pm 0.43$ \\
\hline & & 20.1 & 150.1 & 168 & 180.1 & 189.7 & 203.4 & 210.8 & 230.4 & 232.5 & 250.2 & 250.2 & 250.2 & 252.1 & 570.15 & & \\
\hline \multirow[t]{3}{*}{04} & $\mathrm{~F} 4$ & 30.4 & 151.1 & 155 & 170.1 & 173.1 & 190.2 & 210.1 & 228.6 & 230.1 & 230.1 & 230.1 & 230.1 & 230.1 & 269.41 & & \\
\hline & & 31 & 253.1 & 157 & 173.1 & 175.1 & 193.2 & 220.2 & 230.3 & 233.6 & 233.6 & 233.9 & 233.9 & 232.4 & 269.68 & 269.42 & $269.4 \pm 0.25$ \\
\hline & & 30.5 & 150 & 157 & 175.2 & 190.1 & 189.1 & 217.7 & 228 & 228.9 & 231.1 & 227.2 & 227.2 & 227.2 & 269.18 & & \\
\hline \multirow[t]{3}{*}{05} & F5 & 28.3 & 150.9 & 160 & 170.2 & 188.8 & 190.2 & 193.4 & 198.8 & 198.8 & 198.8 & 210.4 & 211.5 & 212 & 230.39 & & \\
\hline & & 28.6 & 150 & 153 & 15 & 159.2 & 176.4 & 176.4 & 189.1 & 198.8 & 208.8 & 213.5 & 213.5 & 230.42 & .42 & 230.00 & $230.00 \pm 0.71$ \\
\hline & & 28.1 & 151.1 & 151 & 163.9 & 171.1 & 171.1 & 173.2 & 180.8 & 180.8 & 185.3 & 185.8 & 190.4 & 209 & 229.18 & & \\
\hline \multirow[t]{3}{*}{06} & F6 & 27.6 & 160.1 & 161 & 167 & 190.9 & 219.7 & 219.8 & 218.6 & 218.6 & 221.1 & 221.2 & 221.2 & 233.6 & 317.75 & & \\
\hline & & 27.1 & 148.1 & 149 & 160.2 & 189.1 & 201.1 & 215.2 & 218.7 & 230.1 & 230.4 & 230.9 & 230.9 & 230.9 & 317.34 & 319.40 & $317.4 \pm 0.18$ \\
\hline & & 26.9 & 167 & 170 & 172.1 & 190.8 & 210.1 & 215 & 219 & 219 & 222.7 & 222.7 & 222.7 & 231.2 & 317.10 & & \\
\hline \multirow[t]{3}{*}{07} & F7 & 30.8 & 166 & 166 & 166 & 175.5 & 180.4 & 189.1 & 193.3 & 210.5 & 219.6 & 230.8 & 230.8 & 230.8 & 271.75 & & \\
\hline & & 31 & 168.9 & 169 & 169 & 179.2 & 183.1 & 191.7 & 195.2 & 219.7 & 219.7 & 233.8 & 233.8 & 233.8 & 271.29 & 272.62 & $271.62 \pm 0.28$ \\
\hline & & 30.5 & 171.1 & 171 & 181.3 & 181.3 & 1941 & 199.8 & 200.1 & 204.4 & 222.1 & 231.5 & 231.5 & 234.8 & 271.80 & & \\
\hline \multirow[t]{3}{*}{08} & F8 & 33.9 & 209.4 & 181 & 251.5 & 250.5 & 250.8 & 250.8 & 250.8 & 251.8 & 252.9 & 252.9 & 252.9 & 252.9 & 294.99 & & \\
\hline & & 33.4 & 173.9 & 184 & 210.2 & 230.1 & 245.2 & 242.6 & 259.4 & 234.9 & 234.9 & 253.2 & 253.2 & 253.2 & 294.31 & 294.44 & $294.4 \pm 0.45$ \\
\hline & & 33.5 & 160.9 & 173 & 173.2 & 190.8 & 210.4 & 210.4 & 230.1 & 237.5 & 247.2 & 247.2 & 247.2 & 247.2 & 294.03 & & \\
\hline \multirow[t]{3}{*}{09} & F9 & 31.1 & 180.7 & 194 & 201.2 & 205.2 & 205.2 & 212.1 & 121.1 & 213.3 & 213.3 & 215.5 & 215.5 & 215.5 & 224.44 & & \\
\hline & & 30.9 & 179.8 & 190 & 205.5 & 205.7 & 210.3 & 213.1 & 215 & 215 & 215 & 215 & 215 & 216.9 & 224.92 & 224.36 & $224.4 \pm 0.79$ \\
\hline & & 31.2 & 185.1 & 196 & 203.3 & 205.1 & 210 & 210 & 210 & 220 & 221 & 221 & 221 & 217.1 & 223.72 & & \\
\hline
\end{tabular}

Table 5. Cumulative percentage release of drug from swellable oral thin films of metoclopramide hydrochloride from F1 to $F_{9}$.

\begin{tabular}{llllll}
\hline Formulation code & \multicolumn{5}{c}{ Time (minutes) } \\
\cline { 2 - 6 } & 0.00 & 5.00 & 10.00 & 15.00 & 20.00 \\
\hline $\mathrm{F}_{1}$ & 0.00 & 10.0 & 22.4 & 83.4 & 102.4 \\
$\mathrm{~F}_{2}$ & 0.00 & 17.6 & 40 & 79.2 & 102 \\
$\mathrm{~F}_{3}$ & 0.00 & 11 & 32.2 & 65.2 & 100 \\
$\mathrm{~F}_{4}$ & 0.00 & 20.6 & 49.8 & 71.6 & 99.6 \\
$\mathrm{~F}_{5}$ & 0.00 & 14.2 & 33.6 & 63.2 & 101.6 \\
$\mathrm{~F}_{6}$ & 0.00 & 10.2 & 35.4 & 63 & 94.8 \\
$\mathrm{~F}_{7}$ & 0.00 & 7.4 & 22.4 & 57.8 & 98.4 \\
$\mathrm{~F}_{8}$ & 0.00 & 24 & 45.6 & 72.8 & 103 \\
$\mathrm{~F}_{9}$ & 0.00 & 11.6 & 26.8 & 67.4 & 101.2 \\
\hline
\end{tabular}




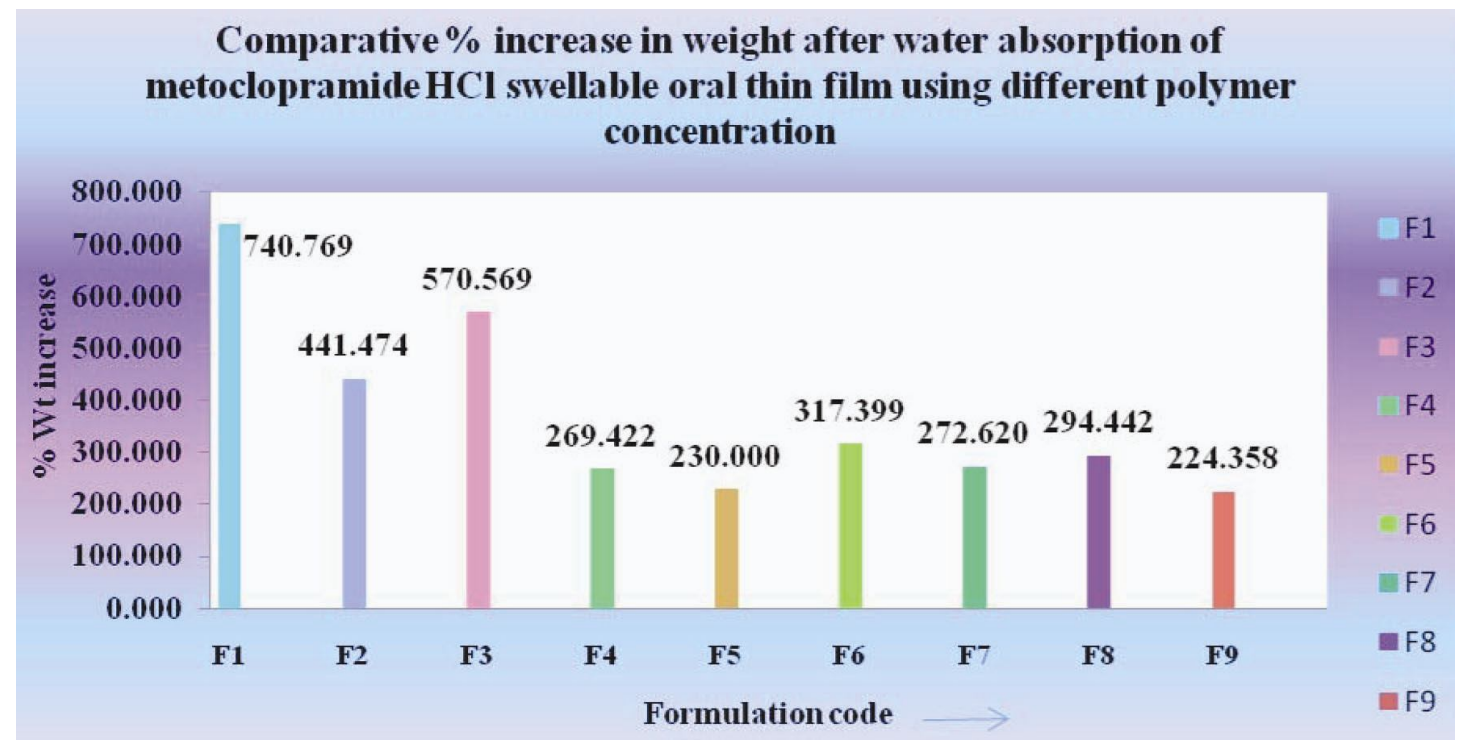

Figure 6. Comparative water absorption by metoclopramide $\mathrm{HCl}$ swellable film using different polymer concentration.

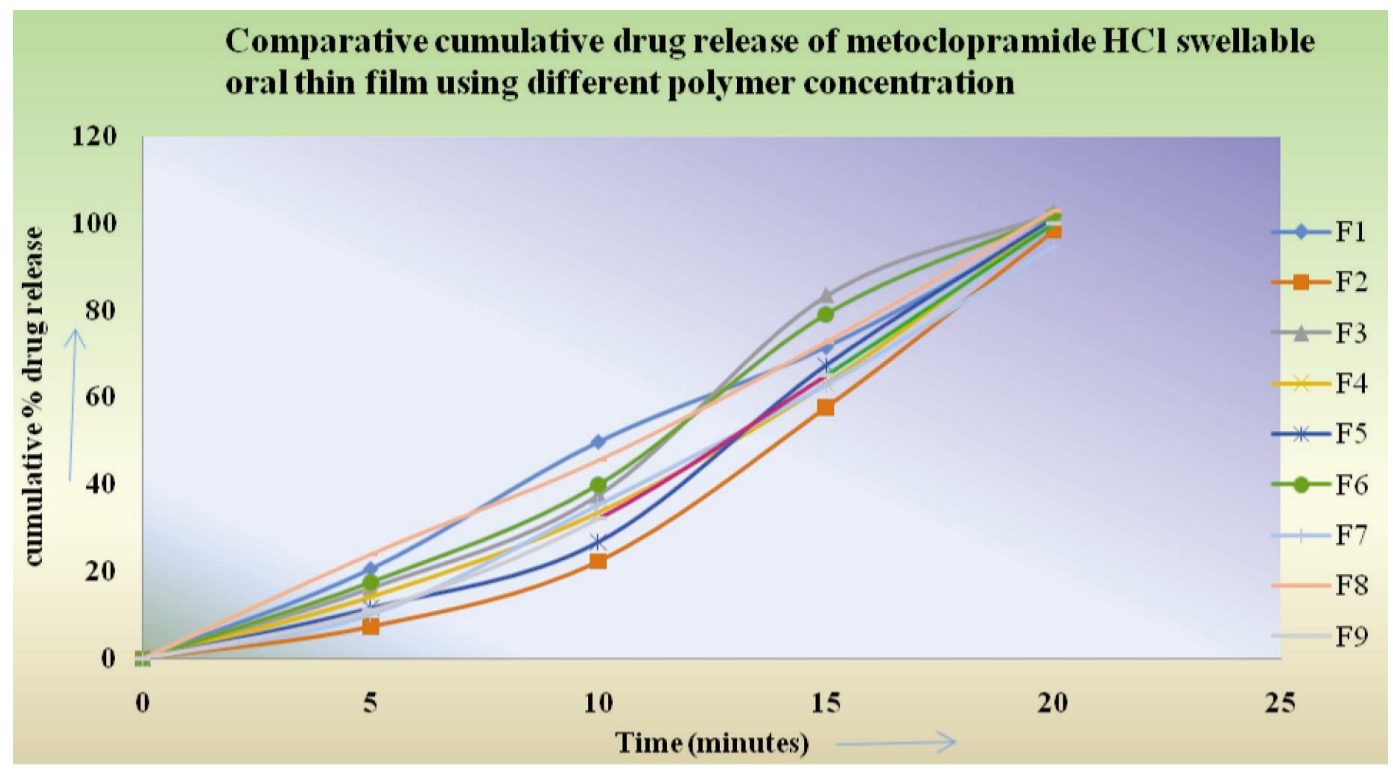

Figure 7. Comparative cumulative drug release of metoclopramide $\mathrm{HCl}$ swellable oral thin film using different polymer concentration metoclopramide hydrochloride from $\mathrm{F}_{1}$ to $\mathrm{F}_{9}$.

Effect of glycerin and povidone $K 90$ on morphogical features and peeling effect of film: Glycerin and Povidone K90 were used in varying quantities in the film formulations $F_{1}$ to $F_{9}$. $F_{1}$ to $F_{3}$ had $0.25 \mathrm{mg} /$ film glycerin and $5 \mathrm{mg}, 10 \mathrm{mg}, 15 \mathrm{mg}$ of Povidone $\mathrm{K} 90$ per film in the drug layer. These films were less glossy in appearance, but were easily peeled from the glass plate. Formulations $\mathrm{F}_{4}$ to
$\mathrm{F}_{6}$ had $0.40 \mathrm{mg} / \mathrm{film}$ of glycerin and $20 \mathrm{mg}, 25 \mathrm{mg}, 30 \mathrm{mg}$ of Povidone K90 per film. These films were glossier compared to $F_{1}$ to $F_{3}$, peeling of these film formulations were comparatively more difficult. Formulations $\mathrm{F}_{7}$ to $\mathrm{F}_{9}$ had $0.55 \mathrm{mg} / \mathrm{film}$ of glycerin and $35 \mathrm{mg}, 40 \mathrm{mg}, 45 \mathrm{mg}$ of Povidone K90 per film. These films were the most glossy, peeling of these film formulations the most difficult of all. 


\section{Comparative \% drug content of swellable oral thin film of metoclopramide $\mathrm{HCl}$}

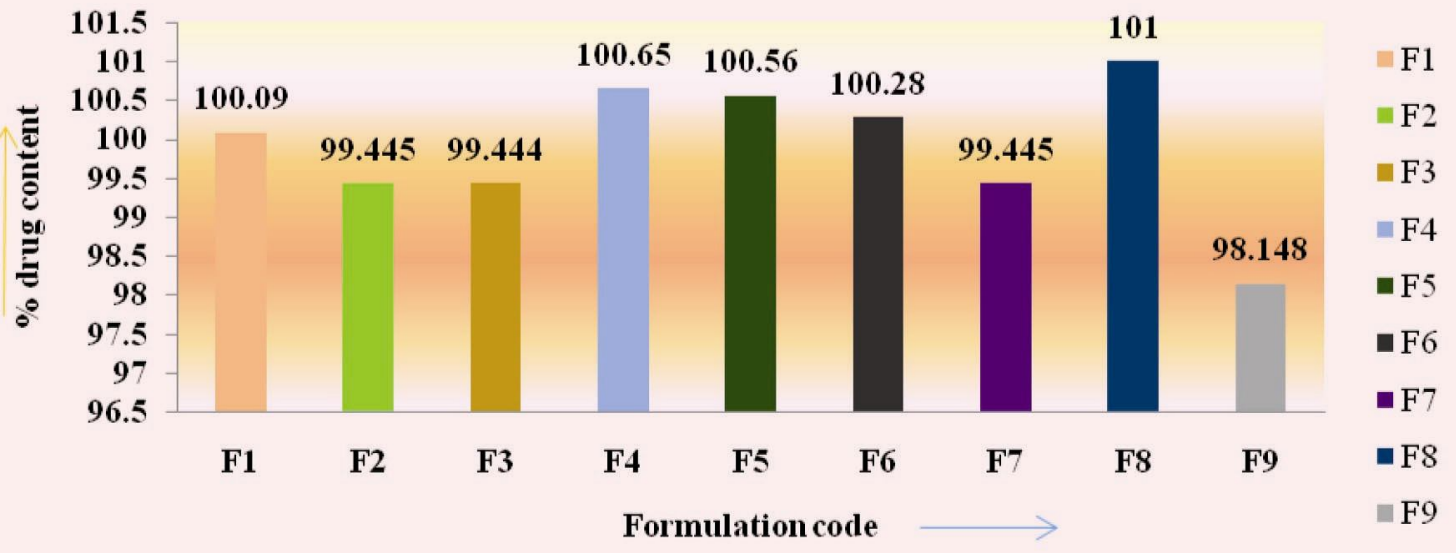

Figure 8. Comparative \% drug content of swellable oral thin film of etoclopramide $\mathrm{HCl}$.

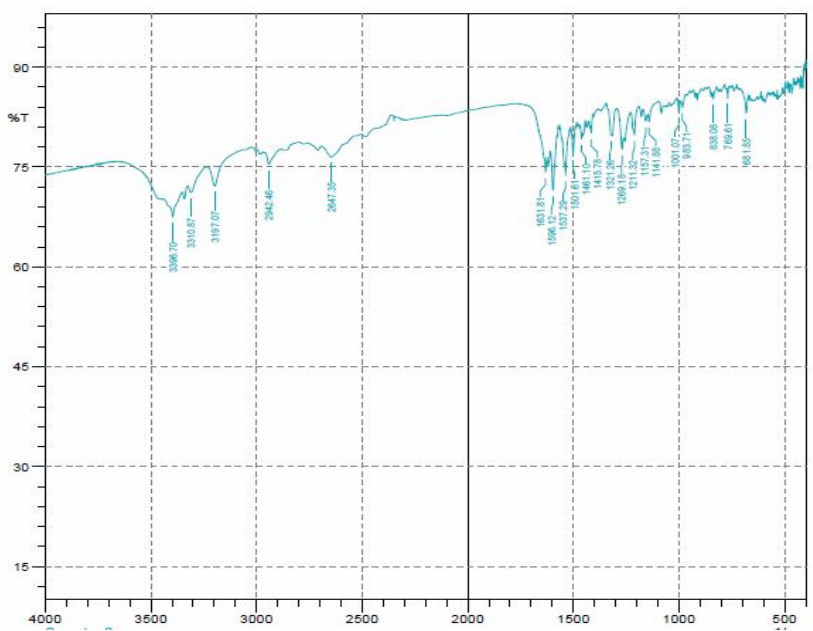

Figure 9. FT-IR spectrum of metoclopramide hydrochloride standard.

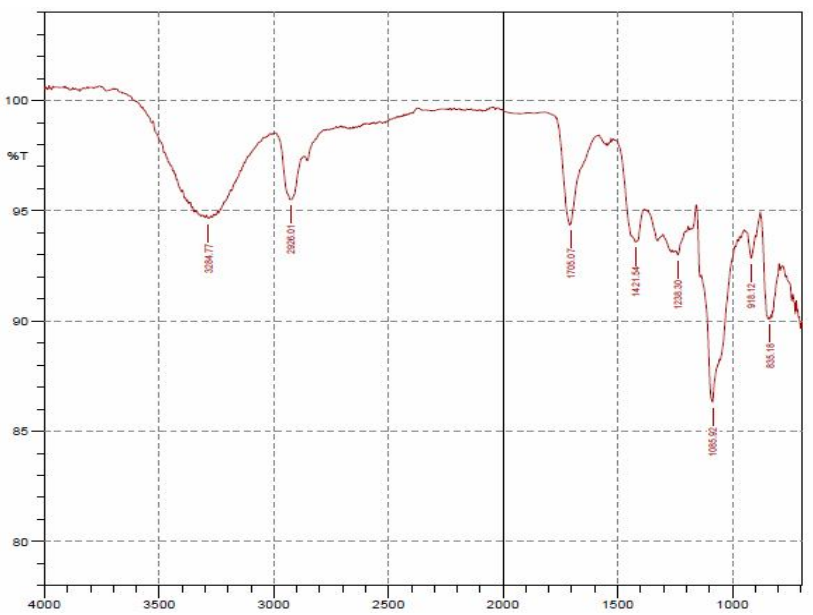

Figure 10. FT-IR spectrum of swellable oral thin film of metoclopramide hydrochloride. 
Table 6. Various properties of swellable oral thin film of metoclopramide HCl.

\begin{tabular}{cccccc}
\hline F code & Mass $(\mathrm{mg}) \pm$ S.D & $\begin{array}{c}\text { Thickness of film }(\mathrm{mm}) \\
\mathrm{n}=10\end{array}$ & $\begin{array}{c}\text { Linear expansion } \\
\text { co-efficient }(\mathrm{n}=10)\end{array}$ & $\begin{array}{c}\text { Amount of water } \\
\text { absorbed }(\%)\end{array}$ & Drug content $(\%)$ \\
\hline $\mathrm{F}_{1}$ & $29.44 \pm 0.412$ & $97.8 \pm 0.919$ & $50.167 \pm 0.289$ & $740.8 \pm 0.685$ & $100.09 \pm 0.893$ \\
$\mathrm{~F}_{2}$ & $32.80 \pm 0.343$ & $120.5 \pm 0.527$ & $45.00 \pm 0.00$ & $441.5 \pm 0.376$ & $99.445 \pm 0.608$ \\
$\mathrm{~F}_{3}$ & $39.09 \pm 0.513$ & $183.10 \pm 0.738$ & $40.167 \pm 0.289$ & $570.6 \pm 0.425$ & $99.444 \pm 0.881$ \\
$\mathrm{~F}_{4}$ & $49.47 \pm 0.457$ & $180.40 \pm 0.516$ & $30.167 \pm 0.289$ & $269.4 \pm 0.250$ & $100.65 \pm 0.817$ \\
$\mathrm{~F}_{5}$ & $52.58 \pm 0.358$ & $180.00 \pm 0.816$ & $25.00 \pm 0.00$ & $230.00 \pm 0.706$ & $100.56 \pm 0.817$ \\
$\mathrm{~F}_{6}$ & $57.370 \pm 0.858$ & $210.70 \pm 0.823$ & $20.167 \pm 0.289$ & $317.4 \pm 0.179$ & $100.28 \pm 0.584$ \\
$\mathrm{~F}_{7}$ & $64.465 \pm 0.343$ & $238.20 \pm 0.919$ & $20.333 \pm 0.289$ & $271.62 \pm 0.283$ & $99.445 \pm 0.608$ \\
$\mathrm{~F}_{8}$ & $69.940 \pm 0.638$ & $256.50 \pm 0.707$ & $10.667 \pm 0.289$ & $294.4 \pm 0.450$ & $101.00 \pm 0.739$ \\
$\mathrm{~F}_{9}$ & $71.150 \pm 0.242$ & $269.60 \pm 0.843$ & $5.00 \pm 0.00$ & $224.4 \pm 0.786$ & $98.148 \pm 0.835$ \\
\hline
\end{tabular}

Trinocular microscopic imaging: Trinocular microscopic imaging was done and encircled drug molecules in povidone $\mathrm{k} 90$ matrix was observed (Figure 11).

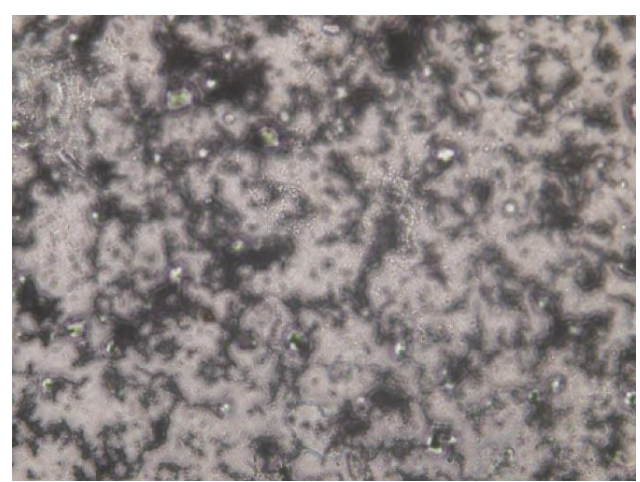

Figure 11. Trinocular image of metoclopramide hydrochloride swellable oral thin film (Batch $\left.\mathrm{F}_{1}\right)$.

\section{Conclusion}

Swellable oral thin films are intended for the application in the oral cavity. These noble dosage forms are promising, especially for use with pediatric and geriatric patients. Metoclopramide hydrochloride is a widely used antiemetic drug. In the present study, a sandwiched swellable oral thin film was formulated which can be easily swallowed without the need of water. Solvent casting method was successfully used in manufacturing of the film. From the present research, we can conclude that metoclopramide hydrochloride was successfully prepared as swellable oral thin film using Povidone K90 as the drug carrier and polyvinyl alcohol as the gel-forming polymer. The method of manufacturing was simple, less time consuming and cost effective. However, further studies on formulation optimization, compatibility, stability, palatability, release kinetic studies are needed to confirm the appropriateness of this formulated orally swellable thin film.

\section{References}

Ahmed, M.G.., Kumar, K.J.B. and Kumar, S.B.P. 2010. Formulation and evaluation of nifedipine transdermal patches. J. Pharm. Res. 3, 1785-1787.

Committee for medicinal and products for human use, European medicines agency, EMEA, Reflection paper. 2006. Formulation of choice of the pediatric population, pp. 4-45

Hideaki, O., Eiji, S., Yusaku, S., Kaisuke, Y., Yasunari, T., Masaru H., Eiji, N., Kaname, N., Toru, S., Mikoto, B. and Saitoh, E. 2008. Development of an easily swallowed film formulation. Int. J. Pharm. 35, 62-66.

Prabhakara. P., Ravi, R., Marina, K., Vijaynarayana, K., Ullas, D, Harish, N.M., Shastry, C.S. and Charyulu, R.N.. 2011. Formulation and evaluation of fast dissolving films of levocitirizine dihydrochloride, Int. J. Pharm. Investig. 1, 99-104.

Raju, S., Reddy, P., Kumar S.V., Deepthi, A., Reddy, K. and Reddy, P.V. 2011. Flash release oral films of metoclopramide hydrochloride for paediatric use, formulation and in-vitro evaluation, J. Chem. Pharm. Res. 3, 636-646.

Sagraves, R. 2006. Pediatric Dosing and Dosage Forms, Chapter 189, Encyclopedia of Pharmaceutical Technology, Third edition.

Saritha, T. and Kumar, Y.S. 2013. Design and in vitro evaluation of orally disintegrating tablets of metoclopramide. Int. J. Pharm. Bio. Sci. 4, 424-429.

Shahriar, N. and Islam, S.I. 2013. Preparation of gastroretentive floating pellets of metronidazole. Bangladesh Pharm. J. 16, 107-105.

Sultana, F., Arafat, M. and Pathan, S.I. 2013. Preparation and evaluation of fast dissolving oral thin film of caffeine; Int. J. Pharm. Biol. Sci, 3,153-161.

USP 2012.Nomenclature Guidelines, General Chapter <1121> Nomenclature. 
